\title{
I AM WORTHY, I WANT, AND I CAN: THE SOCIAL IMPLICATIONS OF PRACTICING PERSONAL DEVELOPMENT
}

\author{
ELENA TRIFAN ${ }^{1}$
}

\begin{abstract}
This paper addresses the consequences of practicing personal development upon the daily life and interactions of individuals. In this context, I will describe how practitioners are applying the principles and techniques of personal development in order to transform the way individuals are relating to themselves and to others. In parallel, I will analyse how the ideology of personal development is assumed, by negotiation, in connection with the neoliberal project. This article aims to bridge a gap in the literature by showing how practicing personal development can restructure everyday experiences, emphasizing the negotiation of the intrinsic values of personal development techniques and how it (re)configures relationships and social interactions.
\end{abstract}

Keywords: personal development, neoliberalism, everyday practices, relationships

\section{Introduction ${ }^{2}$}

The most common expression in books, courses, or workshops for personal development is "You are the most important person in your life!" At first glance, the discussions with people involved at different levels in the practice of personal development - from employees for whom personal development trainings are part of their job to individuals passionate about the field - are devoid of political content, as there are no explicit references to various doctrines or ideologies. Practitioners make no assumption that such practices are connected with political or ideological goals. However, during my fieldwork ${ }^{3}$ I noticed

${ }^{1}$ PhD Student, SNSPA Bucharest, email: trifan.elena@gmail.com.

2 The author was a beneficiary of the project POSDRU/159/1.5/S/134650 "Scholarships for pre-doctoral and postdoctoral fellow young scientists in the fields of Political Science, Administrative Science, Communication Sciences and Sociology".

3 The article is part of my PhD fieldwork for which I have employed different methods of research. I have attended sixteen personal development workshops and presentations; I have conducted thirty interviews with practitioners and participants in personal development activities; and made a content analysis of personal development blogs and sites. 
the reproduction of a certain type of rhetoric related to an ideology. This rhetoric goes hand in hand with the broader political landscape in Romania, with views favouring technocracy, and the public rejection of politics in general and of political parties in particular. Following the definition of Antonio Gramsci (1971), I understand ideology as a field of practices, principles and dogmas that have a material and institutional nature through which individuals are constructed; personal development is therefore shown to be a form of ideology that is closely related to the neoliberal project. Thus, the motto "You are the most important person in your life!" can be translated as "You are responsible for your own life".

The premise underlying my argument on how changes are brought forth by personal development practices is that such practices are tools through which self-governing individuals are constructed in a neoliberal context, with consequences requiring the reconfiguration of social relations.

\section{Personal development: culture, governmentality, globalization}

Neoliberalism is an intensely debated concept in anthropology and the social sciences, especially from a critical point of view. Mathieu Hilgers (2010) distinguishes between three approaches to neoliberalism in anthropology. Comaroff and Comaroff (2003) see neoliberalism as culture: for them, culture is moulded by an ethics of life, and for neoliberalism this is the belief that wealth can be magically acquired. The second approach sees neoliberalism as a system. David Harvey $(2002,2005)$ is the most famous proponent. In his classical work, The condition of postmodernity (2002[1989]), he analyses how the time-space compression interferes with the transformation from a fordist system of production to a post-fordist system, based on flexible accumulation. In A Brief History of Neoliberalism, Harvey (2005) defines the concept:

Neoliberalism is in the first instance a theory of political economic practices that proposes that human well-being can best be advanced by liberating individual entrepreneurial freedoms and skills within an institutional framework characterized by strong private property rights, free markets, and free trade. The role of the state is to create and preserve an institutional framework appropriate to such practices (2005: 2).

The last approach sees neoliberalism as governmentality. It was developed by Foucault in The Birth of Biopolitics (2007) and describes the implementation of the modern non-repressive forms of disciplinary power of the state, through institutions that determine individuals to govern themselves. Rose (1998) argues that psy-sciences are forming self-governing citizens that are learning 
to govern their own lives. Ong $(1987,1999$, and 2006) argues that neoliberalism is at the intersection of the Marxist and Foucauldian perspectives. For Ong (2006), following the discussion initiated by Rose and Miller (1992), neoliberalism describes a new relationship between government and knowledge through which the activities of government are reformed as non-ideological and non-political issues in need of technical solutions. Thus, neoliberalism as technology governance is a thoroughly active way of rationalizing governance and self-governance.

Among the first works that investigated self-help practices (part of personal development practices) are those of Anthony Giddens (1991). In his analysis of self-help groups, like AA (Alcoholics Anonymous) and self-help books, he argues that such practices comfort the self because they offer more possibilities than traditional practices. According to Giddens, the society is undergoing a process of de-traditionalization: religious values are debated and replaced, hence things are not pre-given anymore, but they must be constructed. Self-help literature and other self-help practices play a very important role in this process. Giddens's sociological approach is not critical of self-help, questioning how the latter helps its subjects. If for Christopher Lasch (1979), who accomplished one of the first analyses of the therapeutic culture in the United States, the on-going self-monitoring was a sign of narcissism, for Giddens (1991) such a phenomenon contributes to the development of the reflexive self.

Distinct types of researches analyse personal development as part of the therapeutic culture. Building on case studies from justice, education, social security policy and political rhetoric, James Nolan (1998) develops the argument that the therapeutic gaze has become a form of cultural capital present in state institutions. He criticizes this phenomenon considering its consequences upon the replacement of the traditional values and upon the transformation of public life. Nolan (1998) defines four characteristics of the therapeutic ethos. The first one is an emancipated self, which is based on efficiency, productivity and cost-control effectiveness, alongside self-actualization, self-fulfilment and human dignity. The second one has to do with the pathologization of human behaviour, accomplished through the invasion of public sphere with expressions of personal manifestation. A third characteristic is victimization, where individuals are defined as victims of an oppressive past or of a social environment. The last characteristic is the emotivist ethic, according to which emotions are the underlying reason for moral decisions and for understanding the relationship with others and with oneself. However, Dana Cloud (1998) argues that the therapeutic ideas are used to pacify and weaken the criticism of modern capitalism. Her approach is based on a Marxist rhetoric analysis of several types of cultural products - films, news and feminist politics. The argument she proposes is that the language of therapy has become hegemonic because it is being used by politicians, managers, 
entrepreneurs, feminists and neo-Marxists. They use what Cloud (1998) called personalized and privatized explanations that reject determining systemic social problems such as discrimination, exploitation, poverty and wars. Personal development is an extension of the patriarchal discourse, and the books are a form of consolation, not of strength. On the same note, for Lauren Berlant (2008) self-help writings function like safety valves for feminine anger because they allow women to position themselves in opposition with men without the fear of losing their position and without changing the social order. Also from a feminist perspective, Wendy Simonds looked at the reading of self-help books, concluding that readers do not believe everything they read (Simonds, 1992). She identified several factors that are considered by readers when evaluating a self-help book: whether they are too easy, whether they oversell what they promise to solve, whether they are sensationalistic or overgeneralizing. For Simonds (1992), self-help books promote the perception of the self as a correctable and transformable entity. They belong to the technologies of the self that help transform it into an object to be controlled and rebuilt according to a prescribed ideal (Simonds, 1992).

In a research akin to the one by Simonds (1992), sociologist Paul Lichterman (1992) examined the ambivalence of self-help readers. He argued that readers develop an ambiguous relationship with self-help books because they both trust and distrust them. Even if readers believe such books provide new psychological ideas that validate and label their problems, the author suggests readers share a common understanding about the books. Hence, the pieces of advice in such books can be applied "loosely, tentatively, sometimes interchangeably, without enduring conviction", thus providing a temporary framework of understanding of their issues. Therefore, self-help books are purchased in the absence of legitimate and affordable aid (Lichterman, 1992: 441).

Another important analysis from a sociological point of view is Micki McGee's (2005) description of self-help in the United States. The author introduces the concept of belaboured self, describing the process undergone by the practitioners' selves. The process of self-help has no end; therefore, those who enter this process will work continuously to improve their selves. McGee's (2005) analysis is centred on the categorization of individualism performed by Bellah et al (1998) that differentiates between utilitarian individualism and expressive individualism.

Besides the aforementioned study by Giddens (1991), few studies in sociology had a less critical approach toward self-help. One of them is Worked up selves by Elaine Swan (2010). The author drew from her personal experience as a personal development trainer, and conducted interviews with practitioners to provide response to criticism of current personal development. The book has an interdisciplinary perspective, combining organizational studies and 
sociology. Its main conclusion is that personal development is located at the intersection of traditional therapies and management training. Furthermore, showing that personal development should not be perceived as uniform and context-free as it has been suggested, Swan makes a plea in favour of the importance of research for addressing the diversity of these accounts and practices (2010).

One of the most recent sociological works looking at personal development is Transnational Popular Psychology and the Global Self-Help Industry (Nehring et al, 2016). It describes the hybridization of self-help in China, Trinidad and Mexico and the newest trends of the genre in Britain and the USA, making an argument about the pervasiveness of this type of practices.

Numerous analyses of the self-help phenomenon start from a Foucauldian conceptual framework. Sam Binkley $(2011,2014)$, Karmen Erjavec and Zala Volčič (2009), Rebecca Hazleden (2003), Heidi Marie Rimke (2000), Warwick Tie (2004) argue that the techniques of self-help build self-governing individuals, in the context of the reconfigurations of the relation between state and society. Methodologically, most research is based on content analysis of self-help books. Heidi Marie Rimke (2000) argues that these practices are a tool by means of which citizens are governed and paradoxically their selves gain less autonomy. From the perspective of governmentality, Sam Binkley (2011) examines the importance of positive psychology in imposing the neoliberal project. Karmen Erjavec and Zala Volčič (2009) explore the self-help discourse as part of the managerial discourse in the context of post-socialist neoliberal economy. By using a selfdevelopment radio show as a case study, Tomas Matza (2012) investigates the practice and the policy of self-help in Russia, interrogating the status of neoliberalism in the country. Lisa Blackman (2005) analyses the concept of the dialogical self from psychology, tracing the construction of the concept within the discipline, discussing how it shapes mental pathology and normality, and at the same time linking it with the social and cultural context of flexible capitalism. Rebecca Hazleden (2003) highlights the difference between you and self. The latter is an entity with emotions, feelings, opinions, and ego that you as an objective observer have to guide and control (Hazleden, 2003).

Nickola Pazderic (2013) argues that Heqi ${ }^{4}$ quasi-religious practice "that reflects and reinforces the mandates of individual success as it generates a new collective ethos within an electro-spiritual field (cichang) of universal love" (197), reveals a complex relationship between the neoliberal requirement for success, the perception about power and love, audio technology and the

4 A spiritual practices developed by Michael Chou, drawing from Chinese medicine, which involves breathing exercises, acupuncture centered on qi (energy field) (Pazderic 2013). 
production of the modern self. According to Pazderic (2013), Heqi produces modern subjects in relation to the requirements of global capitalism. In a similar vein, drawing on Foucault's concept of techniques of pastoral power, George Sanders (2012) explains how the construction of self-governed individuals is framed in capitalism. On the same note, Warwick Tie (2004) explores the concept of psychic life of governmentality, using the example of self-help as mean of liberal government. Laurie Ouellette and Julie Wilson (2011) conducted a case study of Dr. Phil's self-help franchise, arguing that it is a way to build neoliberal citizens aimed at women. Elizabeth Puttick (2000) conducted a similar analysis, connecting New Age with current practices. She discussed the secularization of the 1970s movements, which morphed into the contemporary personal development trend, thus passing from a niche to a popular trend with implications in business, environment, the military, and politics. One paper that addresses the same topic as the present article, yet without using data collected through interviews and ethnographic work, is the book Self Optimizing: Social Representations of Self-Help by Ole Jacob Madsen (2015). The author analyses the increased interest in Norway for psy-techniques through the lens of critical psychology and argues that such techniques turn into means of management in the neoliberal system (Madsen, 2015).

Another research strand considers the analyses of the consequences of personal development ethos. Lynne Friedli and Robert Stearn (2015) show how the advanced capitalist economies construct the need for unemployed persons to improve their personal skills. The analysis, based on interviews with recipients of unemployment benefits, explores how the new requirements impact psychologically vulnerable people. Similarly, Kendall et al (2011) discuss the self-management strategies that people with chronic illnesses are advised to apply. The authors critically observe how this approach can produce inequalities. Congruently, addressing the question of inequality, Richard Hackman (2009) writes about the negative consequences of applying ideas from positive psychology in organizations. In addition, another study by Megan Brown (2003), looking at books on business success, analyses how their narratives are (re)constructing a new social Darwinism based on adaptability and flexibility. Brown (2003) argues that such narratives enable a situation to unfold in which the individual finds himself/herself in an endless process of adaptation, naturalizing the idea that anyone can succeed via his/her own willpower.

A third category of studies about self-help, using mainly content analysis of books, employs a Weberian lens to describe how the spirit of capitalism evolved over time. The most important such study is Luc Boltanski and Eve Chiapello's The New Spirit of Capitalism (2016). Drawing on the analysis of management literature from different periods, they show how the spirit of capitalism has 
transformed over time. Their argument is that the 1968 movements in France, criticizing the inequalities and the lack of creativity associated with capitalism, led to a change in the spirit of capitalism by incorporating only the latter part of the criticism. Kobe De Keere (2014) makes a similar argument. He challenges the arguments proposed by Bellah et al (1985), who explains social transformations through the shift from an economic utilitarianism towards an expressive utilitarianism, favouring the explanation of Boltanski and Chiapello (2016) about changes in the ethos of capitalism. Caitlin Forsey (2015) analyses from a Weberian perspective the relationship between self-help, its representatives, whom she called gurus, and their followers. It prolongs Boltanski and Chiapello's (2016) discussion examining

how the calling of the entrepreneur has been supplemented by and transformed into the dharma of the advice guru through a thematic analysis of the manifest and latent content of two self-help texts that display the economic ethics of New Age spiritualism (Forsey 2015:ii).

Barbara Ehrenreich (2009) describes the relationship of American culture with positive thinking from a cultural studies perspective. She looks at how different areas were infused with positive thinking, from medicine, psychology, business and religion, drawing attention to the consequences of this situation. For example, she links the 2007 economic crisis with positive thinking - the latter provided the basis for decisions on decreasing the number of employees or, in general, for decisions taken in the absence of any concrete analysis. In addition, she shows how this type of thinking eliminates critical attitudes toward the system.

Studies that argue that personal development practices are tools through which individuals build self-governance in a neoliberal context (Binkley 2011, Erjavec and Volčič 2009, Hazleden 2003, Matza 2012, Rimke 2000, Rose 1998, Tie 2004 etc.) do not make use of ethnographic examples, as most of them focus on content analyses of books or speeches.

Unlike the strategies adopted in the aforementioned studies, I will describe in this article how undergoing personal development reconfigures the daily activities and interactions, restructuring the way groups and society are perceived. In this description, I will consider Lichterman's (1992) observations that self-help readers engage critically with said books. Similarly, I have observed through interviews and participating in workshops, that informants do not take without consideration the information received. Drawing from the interpretation given by Giddens (1991), who sees personal development techniques as instruments of adapting to postmodernity, I will describe how these solutions are applied and what the consequences of their implementation are. Based on interviews with individuals passionate about personal development, I 
will explore how social relations are reconfigured through the initiation of the personal development process.

The paper contributes to the extended field of researches looking at the way the neoliberal project is applied and interpreted. Therefore, it follows the relationship between neoliberalism and the self mediated by personal development, analysing how they influence each other, what the relationship between neoliberalism and personal development is, and what the relationship between the self and personal development is.

\section{You are the most important person in your life}

Underlying the entire diversity of personal development practices, there is a common denominator that is the requirement for self-centeredness. In each course or workshop that I attended, I heard phrases and expressions repeatedly emphasizing the importance of the relationship every individual must have with himself/herself. This exhortation is most often expressed through the phrase "You're the most important person in your life." The speaker constructs the moment of directing the attention toward the selves of the listeners with the question: "When was the last time you thought about you?" Such a question relies on the assumption that the participants are distracted by everyday routines and are not aware of how they feel and of what their needs are. Therefore, it imagines a separation between the outer life, including a person's social actions, and the inner life, consisting of emotions and experiences according to Tie's (2004) observation about the difference between a person and their inner self. This separation then continues with the idea that the person is the only one who can make a difference regarding how their outer life is shaped. The inner self and the attention granted to the inner life are the main mechanisms by which a person can influence the outer life because the attention directed to the inner life and the outer life means attention towards things that cause satisfaction or dissatisfaction. By identifying and understanding the social situations or circumstances in life, one can act on them. For example, if a relationship with someone is considered inappropriate, it should be discontinued. In the following pages, I describe how people passionate about personal development relate with others and with outer life.

\section{The Management of Social Relations}


The management of relationships is a very popular topic among personal development courses. The Institute for Happiness, where I conducted most of my research, organized events addressing the relationships with others, such as Workshop Happy $U$ - Harmonious Relations: with me and with those around me or Happy $U$ - Positive relationships. With ourselves and with others. Both events were part of a four-meeting workshop about managing relationships, using the PERMA model, borrowed from positive psychology and developed by Martin Seligman (2012), one of the pioneers of positive psychology. PERMA is an acronym that stands for Positive Emotions, Engagement, Positive Relationships, Meaning, and Accomplishment. In Seligman's view (2011), these features are fundamental for individual happiness and psychological welfare. The workshops aimed towards the "conscious and careful cultivation" of love relationships, friendships, or organizational relations. However, in almost every workshop there are discussions about the management of relationships, regardless of theme or purpose. A very common advice found in workshops and courses concerned the examination of the relationship and the possibility of giving up on certain relationships, thought to have a negative impact upon a person and upon her or his personal development process. Giving up on these relationships is based on certain criteria. Maria, for example, describes her experience:

I had very good friends whom I tried to drag along with me. I said, «Come on, I am the locomotive, follow me!» They had such powerful brakes that they would not do anything... They realized that something happened with me, that I was different. Well, they've always considered me different, I was different when I said "yes" to quitting the job at the bank although I was not directly targeted by the layoffs, but I took advantage of the restructuring and I said: «Put me on the list of people fired, don't count on me!». They were shocked: «You have money; you have a position, how come you are leaving just like that? Nobody told you to leave!» That's it. From that moment on, they saw me as very odd, because I did this and because I tried to tell them to take action, to progress, not to settle for anything. However, nothing stuck with them.

(...)

I tried once; I tried twice, until I realized that, in fact, this was starting to get to me. All my zest was drowning and I said «Sorry, I can only do what Andy [author's note: a trainer] explained to me to do when we encounter such a situation». When I realized that I had gotten to this point, it had been a painful decision, it was a sad evening when I got home after the meeting with them. I realized that I actually did not find myself anymore in the group. There is a downside, you grow, but if you are in not in the same environment where you can have some exchanges, the same language, there is nothing to be done because for you the process is irreversible. You can't go back to the state before, once you have seen the beauty on this side, why would you go back to something worse. (Maria, 53 years old, F, economist, coffee shop, 01.03.2016)

When she started the process, Maria felt that she had nothing in common with her old friends. They were preoccupied with holidays and 
shopping, they did not invest in improving their selves - a friend of hers wanted to become a magistrate, but never acted upon it. Therefore, for her friends, personal and professional development was not the priority it was for Maria. Consequently, she considered that this situation could interfere with her own process and decided to break ties with these persons. Their lack of interest was influencing Maria's process of development because their different interests could derail her by tempting her; instead of focusing on the process, she could get distracted. Therefore, how the acquaintances relate with the individual's process of personal development can impact the development of theirs relationship. If friends do not understand the person involved in the process of personal development, the advice of the practitioners is to end the relation.

Denisa shared a similar experience after she started the process, while experiencing a depressive episode during college. She decided to break up with her boyfriend because she considered that he did not understand what she was going through: "I was fighting and I was on the verge of breaking up with my boyfriend because I as a human was changing". She expressed the same desire as Maria, to cut off the relation with people who considered her different after her process began.

Another reason for ending relations after the beginning of the process of personal development has to do with the evaluation of such relations according to the influence they have on someone. The coaches with whom I spoke during the fieldwork I conducted in 2011 gave me examples of clients coming in with an initial problem that had nothing to do with the relation they were in, but who nonetheless renounced the relationship after a period of coaching. In the language of personal development courses, the relations which affect in a negative way the participant are called toxic relations. They can be found in many spheres: love, family, work or friends. Toxic relations are "devouring" the other person; they are consuming their time and energy and they create negative feelings (like sadness or guilt). If translated in conformity with the recommendation from the title of this chapter, a toxic relation is preventing a person from becoming the most important in their lives.

The solution for dealing with a toxic relation is constructed in an individualistic note. Since it does not question the possible cases of abuse, discrimination or exploitation that individuals seeking improvement could be experiencing, the solution provided places the entire responsibility in the hands of the individual. In the following pages, I will provide some examples from the workshops that I attended, describing how the empowerment of the individual who finds himself/herself in an "unhealthy" relationship is constructed. 
During a workshop about emotional development called The Journey, organized by the Institute for Happiness, after the trainer remarked that everything that happens in our lives is our responsibility, someone in the group asked how it could be our responsibility if we have a manager that is treating us unfairly. The trainer said it is the employee's responsibility because it is possible that she sends negative energy that is then reflected in the superior's behaviour towards him/her. The person insisted, wondering how it could still be her responsibility if the manager is "very, very unfair" and behaves the same no matter what she does. Then the trainer said that the responsibility is still hers and that she could get out of the situation by quitting her job.

The example above captures the negotiation and the establishment of the principles of personal development. The trainer had been initiated for a long time with these practices, while the person in the audience was attending one of her first workshops of this kind, and was hearing for the first time this kind of discourse, which explains why she was intrigued by the level of responsibility that was placed upon her.

Even if the relations are not considered toxic for the individual, being concerned for others or constantly taking the others into account are considered unhealthy attitudes. Denisa describes what one of her trainers told her:

\footnotetext{
He was like, "Hey, choose! I mean, you are burning the candle at both ends, I mean it's $\mathrm{OK}$, you're wonderful, what you are doing is great, but let's make some choices" and somehow he was the man who told me "You, you are the master of your life. You're the only one who can make decisions for your own life, stop worrying about others, like your mom, dad, oh my god what is happening, stop worrying about your boyfriend, your friends, your work." This is how I was like; I was neglecting myself pretty much, for others. One way or another, I was neglecting myself, my own self, who I am as a whole and complete person for the way I was perceived. And it was a thing that no one has ever taught me, back when I was 16 years old and I started to build this thing, no one taught me, that I am going to a dead-end. (Denisa, 24 years old, F, student, coffee shop, 23.01.2016)
}

Just like in the case of toxic relations, caring too much for others is a hindrance for taking care of the self. However, worrying about others is a consequence of the individual's behaviour; it has to do with the way the person understands and acts with respect to others, and at same time, it has to do with the self. Starting the process of personal development leads to a reconsideration of the relationships in the lives of individuals and the way they are imagined.

Healthy relationships, from the point of view of the workshops I attended, are built around two major themes: listening and communicating. 
I attended an active listening workshop at the Institute for Happiness. The importance of active listening in human relations from the perspective of personal development is suggested by noticing its absence. "We never listen!", "We talk, but nobody listens" are the catchphrases that start the argumentation for the importance of active listening. These examples are considered the main problems that arise in any kind of relationships. The workshop had three parts: an overview of the topic, an exercise and a discussion. During the exercise, the participants were divided in groups of four, and each of the members had to play all of the following roles: speaker, listener and observer. The speaker had to narrate how his or her day was; the listener had only to listen and look at the person speaking, without asking questions or making other gestures. The observers had to analyse the interaction and then comment on it. In the last part, the participants had to explain what they thought about the exercise and how they felt in the different roles. Active listening is a concept borrowed from psychology and promoted in professional training sessions, which recommends that the listener has to understand what the speaker conveys, and to provide a response to what was said.

Similarly, assertiveness is presented in workshops by describing the opposite behaviour that also seems to be prevalent in everyday interactions, summed up by the phrase "we do not know how to say no". Thus, many workshops about assertive communication are aiming to help participants how to "say no". It is considered important to say "no", because when accepting something for other people, we are actually refusing something for ourselves. Assertive communication reiterates the importance of the self in relation with others and is a technique for the practical implementation of this requirement.

Active listening and assertive communication are only two interpretations of the main components of building healthy relationships: listening and communication. For the participants, they become objectives. They are becoming objectives because they are considered processes. Hence, being difficult to achieve, individuals need to exercise them for a while. Ecaterina describes how she felt when she realized that she has objectives:

Now my objective is to listen, you know (laughs). I arrived at this conclusion, though it feels weird for me to get an idea that I have an objective because I wasn't very organized around objectives, like now I want to do this, you know? Now I want to listen more (laughs). (Ecaterina, 30 years old, masseur, coffee shop, 24.01.2016)

Another consequence of starting the process, after eliminating unhealthy relationships, is replacing them with relationships with people concerned with the personal development process. The volunteers and the employees of the Happiness Institute emphasized this; the Institute was developed because 
Mălina, the founder, wanted a community of people who share the same thoughts. Sorina joined for the same reason - she wanted to be part of a community, in a "positive" space, surrounded by people with similar concerns. Ecaterina also describes her desire to join in:

(...) because I needed to be surrounded by people who have a good state of mind, vitality, who are smiling, you know, compared to what you see on the street. I had a chronic need to communicate with positive people, you know. Perhaps then somehow I changed myself, since I was surrounded by positive people, you know how you change, like a mirror, depending on who you are with. (Ecaterina, 30 years old, masseur, coffee shop, 24.01.2016)

Denisa recollected how when she started attending the Alternative University her life moved there - friends, colleagues, boyfriend, and work. Besides interrupting some relations and beginning new ones, there is an alternative solution for the management of relations, namely introducing old friends to personal development practices in the hope that they will become equally interested. Sharing becomes an imperative of the process. Those who attend the courses also bring friends, in order to make them familiar with the process of personal development. Ecaterina says that if she does not share the information she feels like a "puddle", thus emphasizing the importance of the flow of information, especially because she was herself acquainted with personal development thanks to a friend. Roxana has a similar story: while working for a multinational company, a colleague told her about a course on Neurolinguistics Programing. Consequently, she constructed a technique of personal development that she now practices as a trainer. Adina told me during the interview that recently her boyfriend confessed how he had changed his attitude because of the courses he attended together with her.

Eliminating relationships and choosing new ones are clear manifestations of following the imperative "you are the master of your own life" - the selfgovernance of social life. Moreover, according to some personal development practices, the organization of relations where the individual responsibility prevails applies to any interaction. While working for a company promoting fast learning services, Denisa was having some difficulties in working with children, and she received similar pieces of advice: children are not to blame, but her attitude toward them was. She also received this piece of advice in relation to inanimate objects - her mentor told her that her stress causes the malfunctioning of the printer. Such interpretations are justified by another important idea present in all techniques of personal development: thoughts influence the external life - an idea popularized by the New Thought, a spiritual movement from the beginning of the last century called positive thinking (Starker 1989). Alongside the growing popularity of positive psychology in the 
context of Mihály Csikszentmihalyi's election as president of the American Psychological Association in 2000, the importance of positive thinking has also become an object of interest for scientific research.

\section{Self and Society}

The practitioners' sole responsibility is to educate individuals on how to identify relationships that can be detrimental. This kind of solution seems to be tailor-made for any problem in any society whatsoever. During the research conducted for my BA thesis, an author of personal development books told me that if he would open schools in Africa, the problems there would disappear. Sorina from the Institute for Happiness explained that its purpose is to educate people on positive psychology and achieving happiness. On one of the office walls there is a poster with a famous quote by Mahatma Gandhi - "Be the change you want to see in the world".

I have also observed the online behaviour of some of my informants, taking a stand on certain social issues like supporting the technocratic government or making leaflets about how to behave on public transportation. Similar to supporting a government that has no apparent political orientation, personal development as a solution to social problems is also not seen as an ideological solution. According to neoliberal ideology, the state must move away from handling social protection mechanisms and transfer the responsibility towards the citizens (Harvey, 2005). At a workshop called The Art of Living Happily organized during the fair titled Body Mind \& Spirit, I came across the negotiation of the implementation of these discourses. The trainer held a rather vague speech, without offering too many practical examples about how meditation can be the key to a happy life, and people from the audience started to ask questions. The assumption from which the debate began was that the only way to happiness is meditation:

Participant: Do you think people who live on the street, homeless people, are happy? Trainer: Have you asked them if they are happy?

Participant: No, I ask you. Do you think they are happy? Because you seem to know all the answers. If people meditate, will they have more, more bread for a day? Do you think they can be happy, even if they meditate? Let me give you a concrete example. Last night [it was winter, the author's note], in a rich district in Bucharest, there was a woman in front of a building, on the stairs, outside of course. Can she be happy if she asked me to call an ambulance because she could not stand the cold?

Trainer: There are consequences of her actions that have brought her into this situation. Participant: Maybe she was born on the streets; maybe her parents were also abandoned. [Uproar in the hall] 
Another participant: There are people born on the streets who became successful.

Such an approach can be found in Smiles's Self-help published in UK in 1883 that includes examples of people who achieved upward social mobility through hard work and dedication (1934[1883]). What makes the difference between them and those who remained poor is that they have worked hard to meet their goals, as in the trainer's example. According to this view, if you work hard and do the right thing, in the end you will be successful. Moreover, at an event organized by the Institute for Happiness in order to celebrate the International Day of Happiness, one of the speakers was a person abandoned by his parents. He used to live in an orphanage, but nevertheless eventually became a successful young man.

This extreme form of personal accountability means that you are the most important asset you have. You are the solution for every problem you encounter. Thus, according to the ideology of personal development you are the panacea, not the practices as such. You can solve all your problems. You need to focus more on yourself. You need to operationalize, to know what your skills, abilities, beliefs are. You have to know yourself first; hence, you can use yourself to fix yourself. Unlike in the case of ancient philosophy, where self-knowledge was reserved solely for the elites (Foucault 1995), personal development in the modern society is the responsibility of each person. Everyone becomes a conglomeration of attributes that can be refined and improved to make life better.

Furthermore, practices from the spiritual sphere urge participants to assume full individual accountability. I attended a workshop called Angels Therapy, based on the following principles, according to the description provided by the trainer:

\footnotetext{
Decisions should be made with our soul, using intuition, not through schemes and analyses. The answer comes from your heart. Everything we see around us is signs. Whether you receive a SMS, an e-mail, or read an advertisement - these are all signs those beings of light use to communicate with us. We can find answers in coincidences, and even from a beggar on the street. We must observe what is happening around us and in our souls! Angels communicate with us through intuition, not through the mind. We can be friends with the mind, but the decisions we make with the heart. The first thought we have is the decision we must take. We can communicate directly with archangels, for example use this phrase: «Rafael, please let your green light pass through me». Then, put your hand where it hurts. If you have an emotional blockage, talk with Uriel, the Archangel psychologist, to let him work for you. With Michael, pray for the courage to make changes. Michael deals with cleaning and purification, and Gabriel with communication. (Adina, 37 years old, personal development trainer)
}

What can be drawn from the trainer's explanations is that we are not alone, we can ask for help from the higher beings, creatures from the Bible, to 
help us in the outer and inner life. However, they work as props for our decisions because they are made on first impulse. The trainer notes that decision-making schemes should be avoided, as they are tools built by others, which can deter the decision from us. The discussion in the workshop led to an explanation of the necessity of personal responsibility:

We are the most important people in our lives. If we are not OK with ourselves, how can we have good relations? We have to consider what is good for ourselves. It is important to be attentive and present in our lives, and angels can teach us how to love ourselves. For love, we can work with Jesus and the Virgin Mary. (Adina, 37 years old, personal development trainer)

Then she clearly pointed out what the implications of this might be:

People pick on me because I am too happy, they say, «How can you be so happy when there is war and famine and poverty in the world? » I did not know that it was wrong to be happy. I choose to be happy. I do not care about wars! I am focused on the good things! With each of us, the planet can change. It is not the fault of the system! We cannot blame the neighbour. We can change the world if everyone turns its thoughts toward the planet. How many of you take time for yourselves? (Adina, 37 years old, personal development trainer)

Even if only some practices are based on the idea that the planet can change with good thoughts alone, all have in common the idea that if you live a good life and take care of yourself, things can change. This thinking eliminates any social determination. If you make the right decision, either by using the angels or by having confidence in you, what lies ahead is happiness and success. This type of thinking does not recognize any form of discrimination, unequal access to resources, or the reproduction of classes. In other cases like in the example of the happiness of the homeless person - this type of discourse removes any responsibility towards others, which in the modern state can be regarded as paying taxes that are redistributed towards others in the form of social services. Personal development is closely related to the neoliberal ideology and it works as an instrument for the ideological education of individuals through which they learn neoliberal values. Education is an important subject mentioned in the discussions, for personal development practitioners it is seen as a solution for poverty and the lack of access to resources of individuals. Many personal development courses include plans on how to develop a business, or how to be an entrepreneur. In addition, in order to increase the employees' performance companies use many of the personal development techniques. Companies/corporations support the industry by paying for the products in order to enable the individuals to continue to support the system that allows them to accumulate more capital. 
In the United Kingdom, the unemployed looking for jobs are offered personal development courses (Friedli and Stearn, 2015). This shows how the state's withdrawal from the management of social security is unfolding and how the neoliberal project is protected. In this perspective, the latter does not build inequalities, but provides opportunities for individuals, who can use it to their advantage or not (ibid.).

The personal development discourse uses words that can have different meanings and interpretation for different individuals; a conservative's good thoughts for the planet are not similar with a socialist's good thoughts. Not addressing these differences and leaving the practitioners to discover for themselves what kindness and love mean, the solution can have different outcomes, in terms of saving the planet.

\section{Education}

Practitioners see personal development as a form of education. Many practices explain how to manage everyday situations, drawing from studies in psychology and/or neurosciences, using concepts such as emotional intelligence, assertiveness, active listening, resilience, neural waves etc. They provide guidance on how to control different aspects of living, such as employment or personal relations, adapting them to different situations: how you can convince people to do what you want, how you can have relationships. Therefore, the daily life is split and explained in detail in order to be managed for the achievement of success and fulfilment. This management refers to the fulfilment of expectations that participants have about the conduct of life, which most often refers to work and to a certain extent also to love life, touching on other aspects of the social life by focusing on what I have called inner life.

Firstly, the concern for others implies a lack of concern for their own self, suggesting that the self can be separated from the others or, at least, that it can be built and separated from it. This interpretation is contrary to the sociological theories defining the self as a socially constructed and negotiated concept. According to the theory of personal development, the self can be developed separately from the social context. By proposing to eliminate the concern for others and society in general, what is suggested is the abolishment of the social construction and reconstruction of the self.

Personal development practices highlight the importance of focusing on the self and emotions. Because you are the most important person in your life, what you feel is the most important thing and the only certainty. As you move forward in the process, you receive a form of legitimization of the decisions: a transfer of knowledge from trainer/coach/therapist toward the client takes 
place. The latter will eventually start another transfer, towards those around her/him.

Starting the process of personal development also involves a process of reconfiguration of everyday life. By applying the principles, tips, and indications received through courses and workshops, enthusiasts can act directly on their daily lives. Observing and examining the relationships they have can lead to their termination or to seeing certain people less often. Enthusiasts share and disseminate to all of their discussion partners that they started their "personal development". They participate in personal development events together with their spouses, friends or family members, and some of them start to share their passion about it. By participating in these kinds of events and meetings, some social relations are replaced with others, namely with people with similar interests. Regarding the relation with society in general, practicing personal development implies on the one hand carelessness (Ehrenreich, 2009) and on the other hand a form of involvement by promoting personal development as a solution to social problems of the world. Personal development is seen by practitioners as a mean of educating individuals to overcome some of these inequalities. Therefore, individuals involved with it regard it as a mean of adapting to changes in society.

\section{Conclusions}

This analysis contributes to the debate around the claim that personal development acts as a training tool for citizens in the spirit of the neoliberal project. It takes into consideration the studies that analyse the political discourse related to personal development practices and the link with the neoliberal project that needs self-governing individuals, and adherents to the credo of individual responsibility. Personal development came increasingly to the attention of social science studies, which are especially interested in its implications on social development. Nevertheless, there is no consensus regarding the meaning of these practices. A scholar like Giddens (1991) states that these practices help the individual to adapt to the changes produced in post-modernity. Yet other scholars are critical about the meaning of such practices. Studies argue that such practices work as means of governance for the citizens (Foucault et all, 1988), be it in the interest of the state (Nolan, 1998), or in the interest of the neoliberal system (Rose, 1998). This paper contributes to the debate by showing how personal development influences the everyday lives of the individuals taking part in personal development, and also how such practices are negotiated within the neoliberal technology of subject-making. The changes of the self have 
consequences upon the social configurations through the addition or removal of relationships. Personal and professional life is governed by individual choices. Although most of the practices and practitioners rely on the idea of an authentic self to be liberated from the constraints of others and of society, it comes to be built by applying the principles of personal development and limiting the influence of the social and of the people who also practice such activities. The process involves assessing the social environment that a person inhabits. This evaluation may cause the breakdown of certain relationships, the transformation of others and/or the creation of another, especially with persons also going through a process of personal development. An individual discontinues a relation when it is considered toxic and it diverts the person from the process of development. There is a separation between those who practice and those who refuse to. The bettering of existing relations is part of the same process because it involves the improvement of the practitioners' relationships skills; in the analysis I have presented assertive communication skills and active listening skills. Personal development provides a model for the self-government of social life, which on the one hand empowers the individual, but on the other does not provide any kind of protection from abusive relationships and exploitation. The project is in line with the neoliberal reconfiguration of social security systems that tend to no longer be under state's responsibility, becoming an individual choice; in an individualistic world each person is responsible for his/her own life. Personal development assumes that "you're the most important person in your life", that "you are the only one who can influence your life", therefore when confronted with an injustice you are the only one responsible for finding a solution. A person treated unfairly at the workplace, or a person discriminated against, or a poor person are all responsible for the situation in which they are and are the only ones responsible for their (lack of) social mobility as long as they are exposed to personal development. However, access to personal development practices is restricted by the cost of products and the awareness regarding these practices, making it impossible for disadvantaged individuals to acquire the information provided, about their own responsibility.

\section{REFERENCES}


Bellah, R.N., Madsen, R., Sullivan, W.M., Swidler, A., Tipton, S.M. (1998). Americanii: individualism și dăruire [Habits of the Heart: Individualism and Commitment in American Life]. Bucharest: Humanitas.

Berlant, L. (2008). The Female Complaint: The Unfinished Business of Sentimentality in American Culture. Durham and London: Duke University Press.

Binkley, S. (2014). Happiness as Enterprise: An Essay on Neoliberal Life. New York: SUNY Press.

Binkley, S. (2011). "Happiness, Positive Psychology and the Program of Neoliberal Governmentality." Subjectivity, 4: 371-394.

Blackman, L. (2005). "The Dialogical Self, Flexibility and the Cultural Production of Psychopathology." Theory \& Psychology, 15(2): 183-206.

Boltanski, L., Chiapello, È. (2016). Noul spirit al capitalismului [The New Spirit of Capitalism]. Iași: Editura Universităţii "Alexandru Ioan Cuza".

Brown, M. (2003). "Survival at Work: Flexibility and Adaptability in American Corporate Culture." Cultural Studies, 17(5): 713-33.

Cameron, D. (2007). The Myth of Mars and Venus. Oxford: Oxford University Press.

Cloud, D. (1998). Control and Consolation in American Culture and Politics: Rhetoric of Therapy. Thousand Oaks, London and New Delhi: SAGE Publications,.

Comaroff, J., Comaroff, J. (2003). "Ethnography on an Awkward Scale: Postcolonial Anthropology and the Violence of Abstraction". Ethnography, 4(2): 147-79.

Ehrenreich, B. (2009). Bright-Sided: How the Relentless Promotion of Positive Thinking Has Undermined America. New York: Henry Holt and Company.

Erjavec, K., Volcic, Z. (2009). "Management through Spiritual Self-Help Discourse in Post-Socialist Slovenia." Discourse \& Communication, 3(2): 123-43.

Forsey, C.A. (2015). How to Become an Advice Guru: The New Age Spirit of Entrepreneurial Selfhood. University of British Columbia. https://circle.ubc.ca/handle/2429/54248.

Foucault, M. (2010). The Government of Self and Others. London: Palgrave Macmillan.

Foucault, M. (2007). Nassterea biopoliticii [The Birth of Biopolitics]. Cluj-Napoca: Idea.

Foucault, M. (1995). Istoria sexualității [The History of Sexuality]. Timișoara: Editura de Vest.

Foucault, M., Luther H. M., Gutman, H., Hutton P.H. (1988). Technologies of the Self: A Seminar with Michel Foucault. University of Massachusetts Press.

Friedli, L., Stearn, R. (2015). "Positive Affect as Coercive Strategy: Conditionality, Activation and the Role of Psychology in UK Government Workfare Programmes." Medical Humanities, 41(1): 40-47.

Giddens, A. (1991). Modernity and Self-Identity. Self and Society in the Late Modern Age. Cambridge: Polity.

Gramsci, A. (1971). Selections from the Prison Notebooks, New York: Lawrence and Wishart.

Hackman, J. R. (2009). "The Perils of Positivity". Journal of Organizational Behavior, 30(2): 309-19.

Harvey, D. (2005). A Brief History of Neoliberalism. Oxford; New York: Oxford University Press. 
Harvey, D. (2002). Condiția postmodernității [The Condition of Postmodernity]. Timișoara: Amarcord.

Hazleden, R. (2003). "Love Yourself. The Relationship of the Self with Itself in Popular Self-Help Texts." Journal of Sociology, 39(4): 413-28.

Hilgers, M. (2010). "The Three Anthropological Approaches to Neoliberalism". International Social Science Journal, 61(202): 351-64.

Keere, K. D. (2014). "From a Self-Made to an Already-Made Man. A Historical Content Analysis of Professional Advice Literature." Acta Sociologica, 57(4): 311-24.

Kendall, E., Ehrlich, C., Sunderland, N., Muenchberger, H., Rushton, C. (2011). "SelfManaging versus Self-Management: Reinvigorating the Socio-Political Dimensions of Self-Management." Chronic Illness, 7(1): 87-98.

Lasch, C. (1979). The Culture of Narcissism: American Life in an Age of Diminishing Expectations. New York: W. W. Norton \& Company.

Lichterman, P. (1992). "Self-Help Reading as a Thin Culture." Media, Culture \& Society, 14(3): 421-47.

Lindenburger, S.( 2013). The Religion of Success: The Religious and Theological Roots of the American Success Industry of Self-Help, Personal Growth, and Wealth. Dissertation, The University of Western Ontario, http://ir.lib.uwo.ca/etd/1648.

Madsen, O. J. (2015). Optimizing the Self: Social Representations of Self-Help. East Sussex and New York: Routledge.

Matza, T. (2012). "Moscow's Echo: Technologies of the Self, Publics, and Politics on the Russian Talk Show." Cultural Anthropology, 24(3): 489-522.

McGee, M. (2005). Self-Help, Inc.: Makeover Culture in American Life. Oxford: Oxford University Press.

Nehring, D., Alvarado, E., Hendriks, E.C., Kerrigan, D. (2016). Transnational Popular Psychology and the Global Self-Help Industry. London: Palgrave Macmillan UK.

Nolan, J. L. (1998). The Therapeutic State: Justifying Government at Century's End. New York: NYU Press.

Ouellette, L., Wilson, J. (2011). “Women's Work.” Cultural Studies, 25(4-5): 548-65.

Ong, A. (2006). Neoliberalism as Exception: Mutations in Citizenship and Sovereignty. Durham and London: Duke University Press.

Ong, A. (1999). Flexible Citizenship: The Cultural Logics of Transnationality. Durham and London: Duke University Press.

Ong, A. (1987). Spirits of Resistance and Capitalist Discipline: Factory Women in Malaysia. New York: SUNY Press.

Pazderic, N. (2013). "Recovering True Selves in the Electro-Spiritual Field of Universal Love." Cultural Anthropology, 19(2): 196-225.

Puttick, E. 2000. "Personal Development: The Spiritualisation and Secularisation of the Human Potential Movement." In Beyond New Age: Exploring Alternative Spirituality, edited by Sutcliffe, S., Bowman, M.; Edinburgh: Edinburgh University Press.

Rose, N. (1998). Inventing Our Selves: Psychology, Power, and Personhood. Cambridge: Cambridge University Press.

Rose, N., Miller, P. (1992). "Political Power beyond the State: Problematics of Government". The British Journal of Sociology, 43(2): 173-205. 
ELENA TRIFAN

Rimke, H. M. (2000). “Governing Citizens Through Self-Help Literature.” Cultural Studies, 14(1): 61-78.

Salmenniemi, S., Vorona, M. (2014). "Reading Self-Help Literature in Russia: Governmentality, Psychology and Subjectivity." The British Journal of Sociology, 65(1): 43-62.

Sanders, G. (2012). "Help for the Soul." Journal of Cultural Economy, 5(3): 321-35.

Seligman, M.E. P. (2012). Flourish: A Visionary New Understanding of Happiness and Well-Being. New York: Atria Books.

Simonds, W. (1992). Women and Self-Help Culture: Reading Between the Lines. Diane Publishing Company.

Smiles, S. (1934). Ajută-te singur! [Self-help]. București: Cugetarea.

Starker, S. (1989). Oracle at the Supermarket: The American Preoccupation With SelfHelp Books. Transaction Publishers.

Swan, E. (2010). Worked Up Selves. London: Palgrave Macmillan UK.

Tie, W. (2004). "The Psychic Life of Governmentality." Culture, Theory and Critique, 45(2): 161-76. 